\title{
Study of Chemical and Enzymatic Hydrolysis of Cellulosic Material to Obtain Fermentable Sugars
}

\author{
Myriam A. Amezcua-Allieri, ${ }^{1}$ Teresa Sánchez Durán, ${ }^{2}$ and Jorge Aburto ${ }^{1}$ \\ ${ }^{1}$ Gerencia de Transformación de Biomasa, Instituto Mexicano del Petróleo, Eje Central Lázaro Cárdenas 152, \\ Colonia San Bartolo Atepehuacan, 07730 Mexico City, Mexico \\ ${ }^{2}$ Instituto Tecnológico Superior de Misantla, Km. 1.8 Carretera a Loma del Cojolite, 93821 Misantla, VER, Mexico \\ Correspondence should be addressed to Myriam A. Amezcua-Allieri; mamezcua@imp.mx
}

Received 5 January 2017; Accepted 2 April 2017; Published 7 June 2017

Academic Editor: Raj K. Gupta

Copyright (c) 2017 Myriam A. Amezcua-Allieri et al. This is an open access article distributed under the Creative Commons Attribution License, which permits unrestricted use, distribution, and reproduction in any medium, provided the original work is properly cited.

\begin{abstract}
The objective of this study was to evaluate the chemical and enzymatic hydrolysis using a factorial experimental design $\left(2^{3}\right)$ in order to obtain fermentable sugars from cellulose-based material (CBM) usually used as pet litter. In assessing chemical hydrolysis, we studied the effect of temperature, in addition to $\mathrm{H}_{2} \mathrm{SO}_{4}$ concentration and reaction time, on the production of total sugars, reducing sugars, soluble lignin, carbohydrate profile, furfural (F), and hydroxymethyl furfural (HMF). We performed a response surface analysis and found that, at $100^{\circ} \mathrm{C}, 1 \%$ acid concentration, and $60 \mathrm{~min}$ reaction time, the yields of $0.0033 \mathrm{~g}$ reducing sugar/g biomass and $0.0852 \mathrm{~g}$ total sugars/g biomass were obtained. Under the above conditions, $\mathrm{F}$ is not generated, while $\mathrm{HMF}$ is generated in such a concentration that does not inhibit fermentation. We pretreated the $\mathrm{CBM}$ with $\mathrm{H}_{2} \mathrm{SO}_{4}, \mathrm{NaOH}, \mathrm{CaO}$, or ozonolysis, in order to evaluate the effectiveness of the enzymatic hydrolysis from the pretreated biomass, using an enzymatic cocktail. Results showed that $\mathrm{CBM}$ with acid was susceptible to enzymatic attack, obtaining a concentration of $0.1570 \mathrm{~g}$ reducing sugars/g biomass and $0.3798 \mathrm{~g}$ total sugars/g biomass. We concluded that acid pretreatment was the best to obtain fermentable sugars from CBM.
\end{abstract}

\section{Introduction}

Ethanol production from lignocellulosic material is a topic of interest because it does not undermine crops used for human consumption but it uses various sources of lignocellulosic biomass such as agricultural and municipal solid wastes [1]. In the energy sector, bioethanol has been recently used as an additive, because when mixed with gasoline bioethanol may reduce $\mathrm{CO}_{2}$ emissions and replace the use of toxic oxygenate agents such as methyl tert-butyl ether (MTBE) [2].

Converting lignocellulosic biomass to ethanol involves four stages: pretreatment, hydrolysis, fermentation, and ethanol recovery by distillation [3]. Due to the complex and recalcitrant structure of lignocellulosic biomass, various pretreatment processes are required for carbohydrate hydrolysis, depending on the biomass. Pretreatment increases biomass digestibility for efficient fermentable sugar production, which reduces the cost of bioethanol production [4]. Various pretreatment methods have been suggested, depending on the purpose of removing hemicellulose [5] or lignin from the biomass [6, 7]. Dilute acid pretreatment is a promising pretreatment capable of high solubilization of hemicellulose [8]. This process degrades most of the hydrogen bonds in hemicelluloses and partially degrades cellulose and lignin [9]. In addition, acid pretreatment permits hemicellulose hydrolysis of pentoses and hexoses, removes some of the lignin, and makes the cellulose structure more accessible, so that a fraction can be converted to glucose enzymatically. Pretreatment is a necessary step to alter some structural characteristics of lignocellulose, increasing glucan and xylan accessibility to the enzymatic attack. The structural modifications of the lignocellulose are highly dependent on the type of pretreatment employed and have a great effect on the enzymatic hydrolysis [9] and subsequent steps. The choice 
of pretreatment technology for a particular raw material depends on several factors, some of them directly related to the enzymatic hydrolysis step such as sugar-release patterns and enzymes employed. Thus, the combination of the composition of the substrate in addition to the pretreatment conditions has a great influence on biomass digestibility [10].

This paper proposes the evaluation of a cellulosebased material (lignocellulosic waste: pet litter), to produce bioethanol. The optimization of chemical hydrolysis is described, using an experimental design to determine the best conditions for obtaining high yields of fermentable sugars. Enzymatic hydrolysis of the pretreated biomass with the enzymatic cocktail called Celluzyme $\mathrm{XB}^{\mathrm{TM}}$ is also described, applying pretreatments such as ozonolysis and alkali and chemical pretreatment.

\section{Experimental Methodology}

2.1. Characterization of Cellulose-Based Material. Lignocellulosic biomass, known as "cellulose absorbent" or cellulosebased material (CBM), biodegradable or litter for pet bed, was obtained from a commercial distributor and was characterized in order to know the biomass chemical composition. A total of $250 \mathrm{~g}$ of CBM was ground in a Retsch mill. Then, the ground material was sieved to obtain a 60-80-mesh size. The sample was washed with water at $80^{\circ} \mathrm{C}$, filtered under vacuum, and dried at $50^{\circ} \mathrm{C}$ for $48 \mathrm{~h}$ in a convection oven, Felisa model FE02292A, in order to remove components brought with the cellulose and to avoid any interference. For a proximal chemical composition analysis, determination of ash and moisture was performed. The ash content was determined in a muffle furnace, Lindberg/Blue, BF51866A1 model, at $500^{\circ} \mathrm{C} \pm 25^{\circ} \mathrm{C}$ for 24 hours in order to burn the organic compounds from the biomass. The ash content is reported as percent dry basis, using the formula described by Sluiter et al. [11]. The moisture content was determined in an MB 35 OHAUS thermobalance.

Carbohydrates content, in addition to soluble and acidinsoluble lignin, is obtained through two stages of hydrolysis with $\mathrm{H}_{2} \mathrm{SO}_{4}$. In the first stage, $3 \mathrm{~g}$ cellulose with a particle size of $60-80$ reacted with $3 \mathrm{~mL}$ of $72 \% \mathrm{H}_{2} \mathrm{SO}_{4}(\mathrm{w} / \mathrm{w})$ at $30^{\circ} \mathrm{C}$ for $1 \mathrm{~h}$ in a shaking water bath. Subsequently, the hydrolyzate was transferred to an Erlenmeyer flask and $54 \mathrm{~mL}$ of distilled water was added to obtain a final sulfuric acid concentration of $4 \%(\mathrm{w} / \mathrm{w})$, for a second hydrolysis step in which was carried out the reaction, performed on a SE510 Yamato autoclave at $120^{\circ} \mathrm{C}$ for $1 \mathrm{~h}$. The hydrolysate was filtered under vacuum and the liquid was used for carbohydrates and lignin determination. The solid was washed with distilled water to remove any excess acid present, since the amount of insoluble solid lignin was determined [12].

Total sugars (TS) were determined by the phenol-sulfuric acid method [13], for which glucose was used as a standard and reducing sugars using the method of 3,5-dinitro-salicylic acid (DNS) [14]. The degree of polymerization (DP) of the syrup was obtained in order to evaluate the average monosaccharide units existing, that is, to determine the number of times the repeating monomer unit exits from a chain [15].
The qualitative and quantitative determination of sugars generated was conducted by high-performance liquid chromatography (HPLC). This analysis was performed using a stationary phase with isocratic elution (acetonitrile) and a refractive index detector (RID), or a detector for evaporative light scattering (ELSD), using the Pinnacle II amino column to analyze the monosaccharides and disaccharides, having a detection limit of $100 \mathrm{pg} / \mathrm{mL}$. The evaporative light scattering detector (ELSD) has a flow of $1 \mathrm{~mL} / \mathrm{min}$ at $80^{\circ} \mathrm{C}$, with an injection volume of $10 \mathrm{uL}$, and the mobile phase used is $18 \%$ water and $82 \%$ acetonitrile. The concentration of carbohydrates was calculated by Sluiter et al.s equation [12].

2.2. Chemical Pretreatments. Pretreatments were carried out under conditions set by our group (see Aragon et al. [16] as an example), except for dilute acid pretreatment, for which conditions were set by an experimental design for optimizing chemical hydrolysis.

2.2.1. Acid Pretreatment. The CBM was suspended in $10 \mathrm{~mL}$ of $1 \% \mathrm{H}_{2} \mathrm{SO}_{4}$ (dry basis, $10 \%$ of total solids) in $50 \mathrm{~mL}$ vials. The reaction was carried out for $1 \mathrm{~h}$ in an evaporator at $100^{\circ} \mathrm{C}$ (set conditions in experimental design). After the elapsed reaction time, the reaction vessel was quenched in an ice bath; samples were filtered under vacuum, obtaining a solid and a liquid. From the liquid, we obtained soluble lignin concentration, and the remaining liquid was adjusted to $\mathrm{pH} 7$ with $\mathrm{CaCO}_{3}$ and subsequently centrifuged at 10,000 rpm for $15 \mathrm{~min}$ at $25^{\circ} \mathrm{C}$ to remove excess $\mathrm{CaCO}_{3}$. Liquid was obtained to determinate total and reducing sugars (TS and RS, resp.). The pretreated solid obtained was washed with citrate buffer until the solid had $\mathrm{pH} 4.8$ for subsequent use of enzymatic hydrolysis and for performing the same analysis by infrared (IR) spectrophotometry to analyze the change undergone by functional groups contained in the lignin. Likewise, the washed solid was stored for later use in enzymatic hydrolysis, for which moisture content $(H=73.60 \% \pm 0.7)$ was determined to obtain data on a dry weight basis.

To determine the optimum conditions of pretreatment, we conducted a $2^{3}$ factorial experimental design, that is, three factors with two levels; to determine experimental error, 5 central points were established. During chemical hydrolysis, different $\mathrm{H}_{2} \mathrm{SO}_{4}$ concentrations were used $(0.5,1.0$, and $1.5 \%)$, in addition to temperature $\left(80,100\right.$, and $\left.120^{\circ} \mathrm{C}\right)$ and time $(30,60$, and $90 \mathrm{~min})$. Constant variables were the amount of biomass ( $1 \mathrm{~g}), \mathrm{H}_{2} \mathrm{SO}_{4}$ volume (10 $\mathrm{mL}$ ), and mesh size (60-80). Table 1 shows the factorial design matrix with combinations made according to the established model.

An analysis of variance (ANOVA) was performed using Statistical Product and Service Solutions (SPSS) version 2010, in addition to a principal component analysis (PCA) in Statistica software, version 98. In these analyses, the following dependent variables were considered: total sugars (TS), reducing sugars (RS), degree of polymerization (DP), glucose (GLUC), fructose (FRUC), xylose (XIL), sucrose (SUC), furfural (F), and hydroxymethyl furfural (HMF). These variables can be explained by three factors: time (min), temperature $\left({ }^{\circ} \mathrm{C}\right)$, and acid concentration (\%). A surface response model was subsequently used to analyze the results 
TABLE 1: Factorial experimental design $\left(2^{3}\right)$, including independent variables (temperature, $\mathrm{H}_{2} \mathrm{SO}_{4}$ concentration, and time).

\begin{tabular}{|c|c|c|c|c|c|c|}
\hline \multirow{2}{*}{ Treatment } & \multicolumn{3}{|c|}{ Codified variables } & \multicolumn{3}{|c|}{ Real variables } \\
\hline & $T\left({ }^{\circ} \mathrm{C}\right)$ & {$\left[\mathrm{H}_{2} \mathrm{SO}_{4}\right]$} & Time (min) & $T\left({ }^{\circ} \mathrm{C}\right)$ & {$\left[\mathrm{H}_{2} \mathrm{SO}_{4}\right]$} & Time (min) \\
\hline 1 & -1 & - & - & 80 & 0.5 & 30 \\
\hline 2 & + & - & - & 80 & 1.5 & 30 \\
\hline 3 & - & + & - & 80 & 0.5 & 90 \\
\hline 4 & + & + & - & 80 & 1.5 & 90 \\
\hline 5 & - & - & + & 120 & 0.5 & 30 \\
\hline 6 & + & - & + & 120 & 1.5 & 30 \\
\hline 7 & - & + & + & 120 & 0.5 & 90 \\
\hline 8 & + & + & + & 120 & 1.5 & 90 \\
\hline 9 & 0 & 0 & 0 & 100 & 1 & 60 \\
\hline 10 & 0 & 0 & 0 & 100 & 1 & 60 \\
\hline 11 & 0 & 0 & 0 & 100 & 1 & 60 \\
\hline 12 & 0 & 0 & 0 & 100 & 1 & 60 \\
\hline 13 & 0 & 0 & 0 & 100 & 1 & 60 \\
\hline
\end{tabular}

obtained by the $2^{3}$ factorial design [17] in Statistica software, version 98, taking into account the independent variables that were more significant (obtained from ANOVA and PCA), that is, temperature and acid concentration $(p<0.05)$. Time was standardized as 60 minutes, because it was not a significant variable $(p<0.05)$, and after $60 \mathrm{~min}$ no changes occurred in the response variables.

2.2.2. Basic-Oxidant Pretreatment. A total of $0.05 \mathrm{~g}$ of CBM was placed in a $250 \mathrm{~mL}$ Erlenmeyer flask with a cap, to which $0.3 \mathrm{~mL}$ of a solution of $9 \% \mathrm{H}_{2} \mathrm{O}_{2}$ was added, and then the $\mathrm{pH}$ was adjusted to 11.5 with $\mathrm{NaOH} 2.5 \mathrm{M}$. The reaction was conducted at $35^{\circ} \mathrm{C}$ and $60 \mathrm{rpm}$ for $26 \mathrm{~h}$ on a shaking water bath, whereafter the sample was filtered to produce a liquid and a solid. The liquid was centrifuged at 10,000 rpm for $15 \mathrm{~min}$ at room temperature, and then determination of soluble lignin, TS (phenol-sulfuric acid), and reducing sugar (DNS) was performed. The solid was washed with citrate buffer $(\mathrm{pH}=4.8)$, until the solid remained at this $\mathrm{pH}$, to avoid affecting the enzymatic hydrolysis. For the dry basis weight of material used for the subsequent enzymatic hydrolysis, the moisture content was determined $(H=71.73 \% \pm 0.8)$.

2.2.3. Basic Pretreatment with $\mathrm{NaOH}$. A total of $2 \mathrm{~g}$ of $\mathrm{CBM}$, 60-80-mesh size, was placed in an Erlenmeyer flask with a cap and suspended in $20 \mathrm{~mL}$ of $1 \% \mathrm{NaOH}$; the sample was incubated in an autoclave at $121^{\circ} \mathrm{C}$ for $60 \mathrm{~min}$ so that the reaction could take place. The solid was washed with citrate buffer ( $\mathrm{pH} 4.8$ ). Solid moisture was $74.23 \% \pm 0.6$. Soluble lignin (SL), total sugars (phenol-sulfuric acid), and reducing sugars (DNS) were determined in the remaining liquid.

2.2.4. Basic Pretreatment with CaO. A total of $1 \mathrm{~g}$ of $\mathrm{CBM}$ was mixed with $10 \mathrm{~mL} 1 \% \mathrm{CaO}$. The reaction took place in a $75^{\circ} \mathrm{C}$ water bath with stirring for $60 \mathrm{~min}$. Then, a sample was filtered to obtain a liquid from which the amount of soluble lignin was measured, in addition to total sugars (phenolsulfuric acid) and reducing sugars (DNS). The solid obtained was washed with citrate buffer $(\mathrm{pH} 4.8)$ and the moisture content $(65.99 \% \pm 0.8)$ was determined, to obtain a dry base weight for enzymatic hydrolysis.

2.2.5. Ozonolysis. Ozonolysis was performed in a fixed bed reactor under environmental conditions. To the reactor (a glass column of $75 \mathrm{ml}$ volume, $7 \mathrm{~cm}$ height, and $4.6 \mathrm{~cm}$ diameter), $1 \mathrm{~g}$ of cellulose was added, which was wetted with $1 \mathrm{ml}$ of water for each test. The material was exposed to ozone for $1 \mathrm{~h}$, and during the reaction ozone was wetted with potassium iodide $0.05 \mathrm{M}$ phosphate buffer ( $\mathrm{pH} 7$ ) to prevent dehydration and to determine the amount of ozone that reacted with the sample. Flow rate entrance was $46.6 \pm 5 \mathrm{~L} / \mathrm{h}$ and ozone concentration, which interacted with the sample, was $0.056 \pm 0.03 \%(\mathrm{v} / \mathrm{v})$. A pretreated solid with ozone was obtained and washed with citrate buffer to obtain TS, RS, and soluble lignin. The solid was washed with citrate buffer and the moisture content was determined $(66.24 \% \pm 0.8)$ to obtain $0.1 \mathrm{~g}$ of the material pretreated in dry weight for the enzymatic hydrolysis.

2.3. F and HMF Determination. During chemical hydrolysis, some carbohydrates are formed, which generated products such as F and HMF, which inhibit bioethanol production [18]. These compounds were analyzed by high-performance liquid chromatography (HPLC) with a UV-Vis detector. The sample was filtered with a nylon syringe filter of $0.25 \mathrm{um}$ and $1 \mathrm{~mL}$ was placed in a vial with $1.5 \mathrm{~mL}$ capacity for HPLC F and HMF determination during a period of $15 \mathrm{~min}$, using the calibration curves.

2.4. Enzymatic Activity Determination. The activity of "Celluzyme XB" cocktail from Novozyme was determined through a series of enzyme dilutions. Strips of Whatman filter paper No. 1 were used as a substrate. Paper was placed in a capped vial with $1 \mathrm{~mL}$ of $0.05 \mathrm{M}$ citrate buffer ( $\mathrm{pH} 4.8$ ). $0.5 \mathrm{~mL}$ of each dilution of the enzyme was added to a Syncore evaporator and incubated at $50^{\circ} \mathrm{C}$ and $180 \mathrm{rpm}$ for $60 \mathrm{~min}$. 
TABLE 2: Chemical composition of the cellulose-based material.

\begin{tabular}{lc}
\hline Parameter & Values \\
\hline Soluble lignin in acid (\%) & $10.160 \pm 0.10$ \\
Nonsoluble lignin in acid (\%) & $25.968 \pm 0.10$ \\
Total lignin (\%) & 36.13 \\
Total sugars (g sugars/g biomass) & $0.639 \pm 0.03$ \\
Reducing sugars (g sugars/g biomass) & $0.538 \pm 0.05$ \\
Degree of polymerization & $1.197 \pm 0.07$ \\
TS/TL ratio & 1.77 \\
Ash (\%) & $0.490 \pm 0.06$ \\
Moisture (\%) & $4.410 \pm 0.05$ \\
\hline
\end{tabular}

Once the reaction was completed, the enzyme was inactivated by immersing the tubes in water at boiling temperature, and then the sample was filtered through $0.45 \mu \mathrm{m}$.

Subsequently, the amount of sugars was measured with a glucose calibration curve on a Thermo Spectronic UVVisible spectrophotometer at $540 \mathrm{~nm}$. The amount of released protein was determined by the Bradford method. To use the calibration curves, the amount of sugars present in the target enzyme was subtracted. Total filter paper units (FPU) were determined by the equation described by Sluiter et al. [12].

2.4.1. Enzymatic Hydrolysis. The pretreated samples of CBM were washed with $200 \mathrm{mM}$ citrate buffer $(\mathrm{pH} 4.8)$ in a centrifuge model $5810-\mathrm{R}$ to $10,000 \mathrm{rpm}$ at $25^{\circ} \mathrm{C}$, until the material reached $\mathrm{pH}$ in the range 4-5. A total of $0.1 \mathrm{~g}$ of material was weighed and added to $2 \mathrm{~mL}$ of citrate buffer $(\mathrm{pH}$ 4.8 ) and $0.04 \mathrm{~mL}$ of enzyme cocktail "Celluzyme XB" and incubated at $50^{\circ} \mathrm{C}$ for $1 \mathrm{~h}$. Samples were filtered using a nylon filter of $0.45 \mu \mathrm{m}$. Carbohydrates in the syrup were determined as described above.

\section{Results and Discussion}

3.1. Characterization of Cellulose-Based Material. The main composition of the material is shown in Table 2. We found a total sugar (TS) and lignin (TL) content of 63.9 and $36.13 \%$ $\mathrm{w} / \mathrm{w}$, respectively, with a TS/LT ratio of 1.77 . In accordance with our experience, such TS/LT value is typical for forest residues.

3.2. Chemical Hydrolysis from a Design of Experiments. Conditions for hydrolysis with $\mathrm{H}_{2} \mathrm{SO}_{4}$ were analyzed using an experimental design (Figure 1). Results showed that, by increasing acid concentration, the release of total sugars increases during the chemical hydrolysis, reaching a maximum concentration of $0.274 \mathrm{~g}$ total sugars $/ \mathrm{g}$ biomass at a $\mathrm{H}_{2} \mathrm{SO}_{4}$ concentration of $1.5 \%$ at $80^{\circ} \mathrm{C}$, that is, significantly increasing the solubilization of cellulose for obtaining total sugars, generated in a process in which $1 \mathrm{~g}$ of CBM was treated with $\mathrm{H}_{2} \mathrm{SO}_{4}$ concentration ranging from 0.5 to $1.5 \%(\mathrm{v} / \mathrm{v})$ and at temperature between 80 and $120^{\circ} \mathrm{C}$, the latter being the determining factor in the total sugars released. The results obtained with regard to the generation of total sugars could be because cellulosic biomass is partially hydrolyzed, increasing

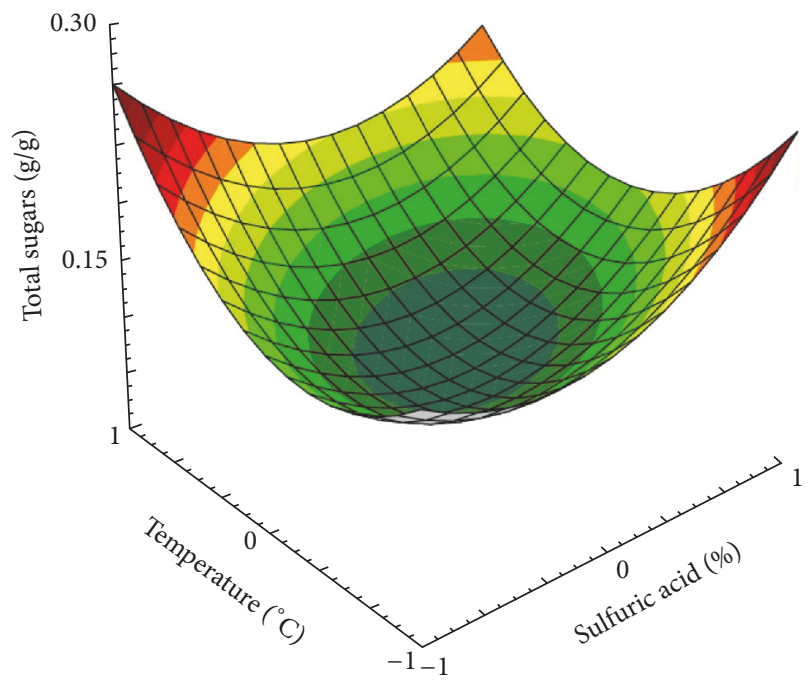

FIGURE 1: Influence of temperature $\left({ }^{\circ} \mathrm{C}\right)$ and diluted sulfuric acid concentration (\%) on the generation of total sugars.

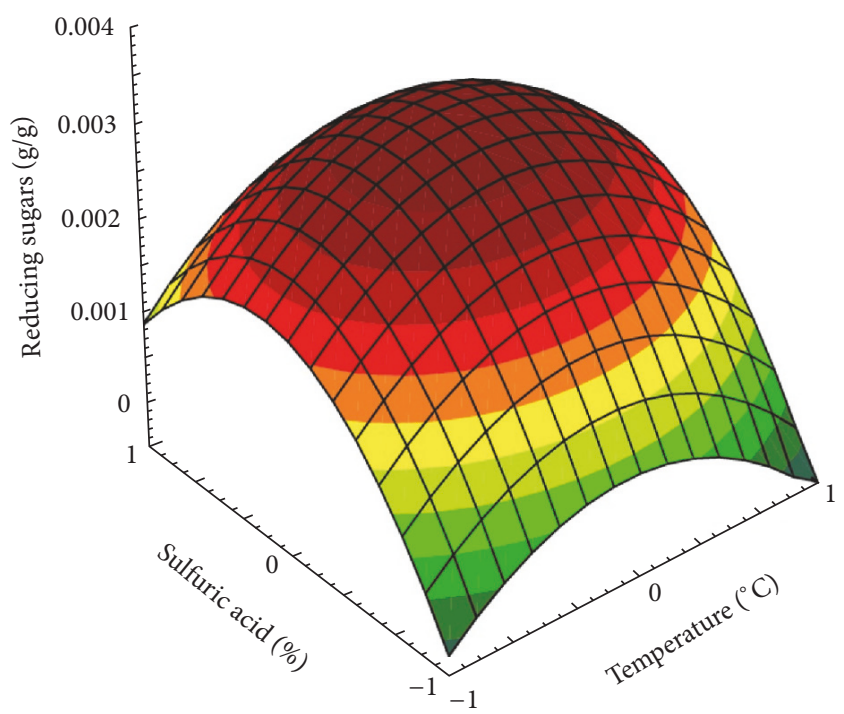

FIGURE 2: Influence of temperature $\left({ }^{\circ} \mathrm{C}\right)$ and sulfuric acid concentration (\%) on the generation of reducing sugars.

the surface and exposure of the cellulose fibers [19], that is, significantly increasing the solubilization of cellulose for obtaining total sugars, generated in a process in which CBM is treated. Time reaction was also studied; however, there was not any significant difference $(p<0.05)$; therefore, total sugars generation consistently increases at minute 60 .

There is a maximum in the production of reducing sugars (Figure 2) at elevated temperatures and the highest dilution of acid. Chemical hydrolysis showed a reducing sugar concentration of $0.0033 \pm 0.0004 \mathrm{~g}$ reducing sugars/g biomass, establishing that favorable experimental conditions for sugars released are $100^{\circ} \mathrm{C}$ and a concentration of $1 \%$ $\mathrm{H}_{2} \mathrm{SO}_{4}$. These factors have a positive effect on the amount of hydrolyzed sugars, playing an important role in separating the cellulose-hemicellulose complex [20]. 


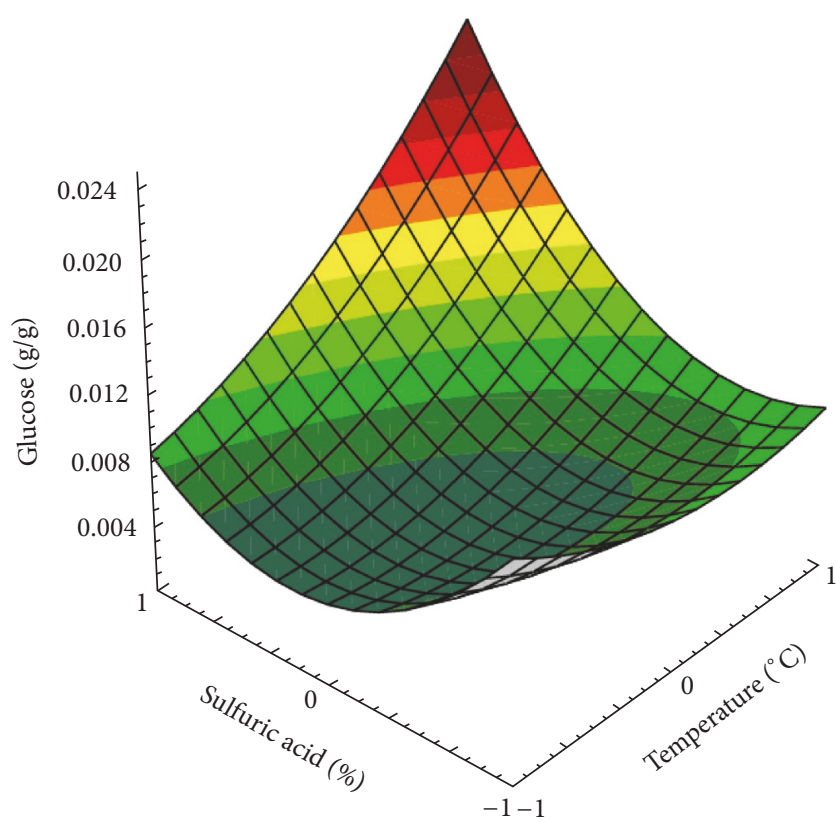

Figure 3: Relationship between temperature $\left({ }^{\circ} \mathrm{C}\right)$ and sulfuric acid concentration (\%) with respect to glucose formation.

The polymerization degree was analyzed in order to assess the average number of units of monosaccharides existing in the extracted polysaccharides [14]. A good efficiency of chemical pretreatment increases the accessibility of glycan to saccharification and therefore obtaining a value of polymerization degree close to one, so that they can be converted to ethanol [21]. According to the results, a degree of polymerization of 29.640 was obtained at $100^{\circ} \mathrm{C}$ and an acid concentration of $1 \%$, which is proven to be the least of the above conditions.

\subsubsection{Generation of Toxic Compounds Derived from Furfural.} During chemical hydrolysis, $\mathrm{F}$ is generated from pentoses and HMF from hexoses [22]. In experiments, degradation products increase in concentration as temperature and $\mathrm{H}_{2} \mathrm{SO}_{4}$ concentration increase, reaching a maximum concentration of $2.8962 \% \mathrm{~F}$ and $3.62 \% \mathrm{HMF}$ at $120^{\circ} \mathrm{C}$ and $1.5 \%$ acid concentration. With respect to toxic compounds during ethanol production [23], what is sought is to have the optimum conditions in which there is no generation of these compounds, or at least not existing in relevant concentrations, by which it was proposed to work at $100^{\circ} \mathrm{C}$ and $1 \%$ acid concentrations, where $\mathrm{F}$ is not generated and HMF is generated below $2.98 \%$. It has been shown that $\mathrm{F}$ concentrations above $3 \mathrm{~g} / \mathrm{L}$ of and $3.2 \mathrm{~g} / \mathrm{L}$ HMF inhibit bioethanol fermentation by 20 and $50 \%$, respectively [24]. Therefore, it can be said that $2.98 \% 5$-HMF does not affect the next steps in the fermentation process for bioethanol production.

3.2.2. Carbohydrate Profile. After applying the chemical hydrolysis to the CBM, liberated cellulose is degraded to glucose by the action of dilute $\mathrm{H}_{2} \mathrm{SO}_{4}$. Figure 3 shows that, at a temperature of $100^{\circ} \mathrm{C}$ and acid concentrations of $1.5 \%$, a maximum concentration of $0.016 \mathrm{~g}$ glucose $/ \mathrm{g}$ biomass is generated. Low concentration of glucose generally indicates that cellulose degradation suffered poor or incomplete hydrolysis; hence, it follows that the chemical hydrolysis is quite selective since the chemical hydrolysis conditions are not so severe as to cause cellulose solubilization, because its crystal structure makes it difficult to complete the hydrolysis [25].

During fructose generation after CBM is hydrolyzed, the increased generation of fructose is conducted at temperatures of $100^{\circ} \mathrm{C}$ and at $1.5 \%$ sulfuric acid concentrations, giving a maximum concentration of $0.00674 \mathrm{~g}$ fructose $/ \mathrm{g}$ biomass. Fructose concentration is not significant when compared with five-carbon sugars such as xylose, yet it is capable of being fermented in smaller molecules and more easily because they are sugars of six carbon atoms, and they are those with greater availability.

Sucrose shows a different behavior to glucose, since it increases at a $1 \%$ sulfuric acid concentration and as temperature increases, thereby obtaining a concentration of $0.006 \mathrm{~g}$ sucrose/g biomass at $120^{\circ} \mathrm{C}$ and $\mathrm{H}_{2} \mathrm{SO}_{4}$ concentration of $0.5 \%$.

Xylose formation is increased with increasing temperature and acid concentration, thus creating a maximum concentration of $0.18342 \mathrm{~g}$ xylose/g biomass. Chains of hemicellulose suffered disruption, generating all possible monosaccharides present in chains, and one of them is xylose, from which a yield of $18 \%(\mathrm{w} / \mathrm{w})$ was obtained. The direct application of chemical hydrolysis to CBM also reduces aggregation between cellulose microfibrils, as well as making direct hydrolysis obtain good yields $(0.008-0.275 \mathrm{~g}$ total sugars/g biomass), depending on the experimental conditions to which the biomass is submitted. Chemical hydrolysis may be used then as a pretreatment that generates soluble sugars but also facilitates further enzymatic hydrolysis as seen by a higher yield ( $0.379 \mathrm{~g}$ total sugars/g biomass) and is discussed below.

3.2.3. Statistical Analysis. The results from ANOVA showed statistically significant differences $(p<0.05)$ between the treatments used. Factors included in the analysis of main components explain $81.4 \%$ of the total variance. The temperature favors the generation of F, HMF, glucose, and xylose; the acid concentration increases the generation of reducing sugars, lignin solubilization, and increased sucrose.

The factors relevant to production of soluble sugars are temperature and acid concentration followed by time. However, we set a reaction time of 60 minutes since we observed maximum generation of soluble sugars. Acid hydrolysis is favored at conditions of $100^{\circ} \mathrm{C}, 1 \%$ sulfuric acid, and a reaction time of $60 \mathrm{~min}$.

Results of the experimental design show that acid concentration was only significant for fructose, glucose, and HMF generation. Time is significant in reducing sugars' generation and consequently the degree of polymerization. The statistical study, based on the $p$ values, shows that only temperature has a statistically significant effect on the chemical hydrolysis, while the other two factors are significant but less significant than temperature.

From response surfaces, PCA, and ANOVA, it was concluded that the optimum conditions to obtain fermentable 


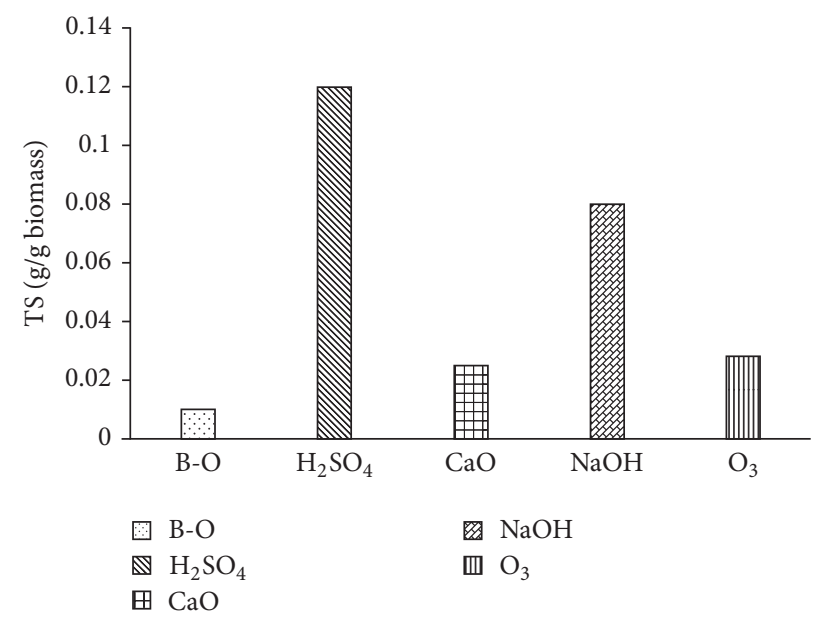

FIGURE 4: Effect of different pretreatments on the generation of total sugars.

sugars from CBM by chemical hydrolysis are $100^{\circ} \mathrm{C}$ for a reaction time of $60 \mathrm{~min}$ and $1 \%$ acid concentration.

3.3. Enzymatic Hydrolysis. Enzymatic hydrolysis was performed on solids obtained from the pretreatment, in order to evaluate the effect of each pretreatment with respect to the generation of soluble sugars, so that the effect of different pretreatments on hydrolysis with enzyme cocktail "Celluzyme XB" is studied.

3.3.1. Pretreatments Applied to CBM. Figure 4 shows the effect that different pretreatments had on the CBM with respect to the generation of total sugars. Acid pretreatment resulted in a higher concentration of total sugars having a concentration of $0.115 \mathrm{~g} \pm 0.003 \mathrm{~g}$ total sugars/g biomass for $10 \%$ solids. In the other pretreatments, sugars release is also promoted, however in smaller amounts.

Reducing sugars measured by the DNS technique showed that dilute acid pretreatment presented a concentration of $0.0045 \pm 0.004 \mathrm{~g}$ reducing sugars/g biomass, being the best treatment in separating the cellulose-hemicellulose complex. Possibly, the failure in finding reducing sugars from alkaline pretreatments was mainly due to how they produce swelling of cellulose, but not necessarily reaching hydrolysis of reducing sugars present or their chemical composition changes [26]. Although the applications of basic pretreatment with $\mathrm{CaO}$, basic pretreatment with $\mathrm{NaOH}$, oxidizing basic pretreatment, and ozonolysis are effective because they improve the opening of cellulosic fibers [10], they do not degrade sugars at this stage, that is, only making the material susceptible to enzymatic attack.

Efficiency of different pretreatments with respect to lignin solubilization (Figure 5) showed that basic-oxidant pretreatment solubilized $1.53 \%$ lignin, being the best pretreatment. This behavior was probably because treatment with diluted $\mathrm{NaOH}$ produces a swelling in the biomass, leading to an increased internal surface area and a decrease in crystallinity and structural separation joints between lignin and carbohydrates, causing a break in the structure of lignin.

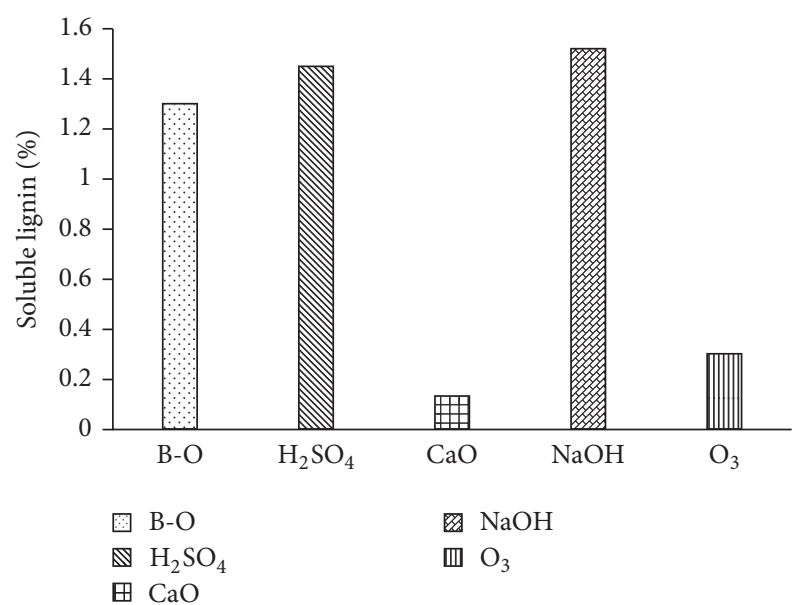

Figure 5: Concentration of soluble lignin based on the different pretreatments made to cellulose-based material.

The mechanism of the alkaline hydrolysis of biomass seems to be based on the saponification of intermolecular ester bonds linking the xylan of the hemicellulose and other components [27]. It is noteworthy that the effectiveness of the pretreatment depends on the lignin content of the material to be pretreated.

Dilute sulfuric acid pretreatment with $1.45 \%$ solubilized lignin is the second best pretreatment to solubilize lignin, and such pretreatment already has been reported because of its high reaction rates and its effective hydrolysis of cellulose. However, lignin does not dissolve as well as other pretreatments but rather increases yields of enzymatic hydrolysis [12].

\subsubsection{Effect of Various Pretreatments on Polysaccharides} Chemical Structure Using Infrared Spectrophotometry. Infrared spectra of the five pretreatments (dilute acidic pretreatment, basic-oxidant pretreatment, basic pretreatment with sodium hydroxide, basic pretreatment with calcium oxide, and ozonolysis) performed on solids (insoluble lignin) were analyzed in the region of $400-4000 \mathrm{~cm}^{-1}$ wavenumber (Figure 6). These spectra show structural differences in nonpretreated solid and treated solids. The absorption peaks observed in the infrared spectrum were attributed to vibrations of stretching peaks through structural changes with respect to the hydroxyl groups that are in a region between 3550 and $3300 \mathrm{~cm}^{-1}$. Comparison between spectra from pretreated and nonpretreated biomass shows similar patterns; however, bands from treated material have a stretching vibration in their $\mathrm{OH}$ bands; that is, the area is augmented. In the region between 1500 and $1400 \mathrm{~cm}^{-1}$, there are peaks that are very similar to those identified by Pearl [28] and Singh et al. [29], representing vibrations associated with guaiacyl and syringyl units (monomers of lignin), which are the same as shown in the spectra obtained, however with greater intensity of guayacil bands. Another important value is at approximately $1160 \mathrm{~cm}^{-1}$ which represents in-plane deformation of $\mathrm{CO}$ bonds in aliphatic secondary alcohols and ethers. At $1265 \mathrm{~cm}^{-1}$, there is stretching of the $\mathrm{CO}$ bonds 
TABLE 3: Enzymatic activity of the enzyme cocktail Celluzyme XB.

\begin{tabular}{lccc}
\hline Enzyme & Protein $(\mathrm{mg} / \mathrm{mL})$ & Cellulolytic activity $(\mathrm{FPU} / \mathrm{mL})$ & Specific activity $(\mathrm{FPU} / \mathrm{mg}$ protein) \\
\hline Celluzyme XB & 77.11 & 217.65 & 2.82 \\
\hline
\end{tabular}

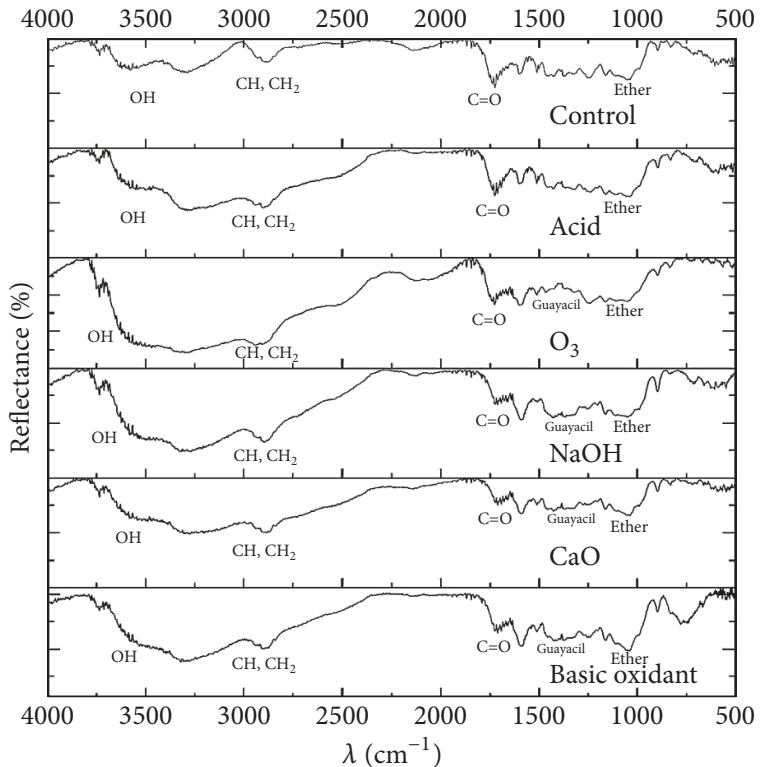

FIGURE 6: Spectrum of different pretreatments analyzed by infrared spectroscopy.

representing vibration in the rings of the guayacil with more units of carbon-oxygen bonds [30].

The $\mathrm{OH}$ group initiates substitution reactions on the solid pretreated with dilute acid. This condition causes the transformation of the hydroxyl group to an allyl ether and ultimately the ether is substituted with an acid group. The benefit of this reaction is that the presence of the acid group in the molecule causes the lignin polymer to be soluble in water [30].

The ester linkage containing glucose monomers in a polymer chain is the most important lignin link. Therefore, ether bond cleavage can lead to separation of lignin from the polysaccharide matrix and degradation of the polymers of monomeric sugars and lignin fragments. The cleavage of this bond occurs through solvolytic reactions, which may take place under acidic or alkaline conditions or by different mechanisms. In the case of lignin, under acidic conditions, the ether bond is converted to $\mathrm{OH}$ and then converted to carbonyl or carboxyl before being fragmented into molecules of C3 and C2. Under alkaline conditions, the mechanism is different and the end result is not a fragmented side chain, but the separation of the aromatic rings. In the case of cellulose cleavage of ether bonds, this may be contained either in acidic or in alkaline media. When acidic media are used, the acid acts as a catalyst for the protonation of the oxygen atom. The charged group leaves the polymer chain and is replaced by the hydroxyl group of water. The reaction that occurs is a firstorder reaction.
In order to determine which pretreatment is more efficient for delignified cellulosic material, a comparative analysis was performed before and after pretreatment. In the CBM, nonpretreated well-defined peaks are shown (Figure 6) with vibration of $\mathrm{OH}$ groups, in addition to their $\mathrm{CH}$, $\mathrm{CH}_{2}$, carboxylic acids, phenolic ethers, aromatic groups, and characteristic guaiacyl lignin groups. However, treatment with dilute $\mathrm{H}_{2} \mathrm{SO}_{4}$ shows similarity in their spectra with respect to the original sample, but functional groups are present in stretching vibrational peaks due to the effect of the pretreatment that was applied.

For basic pretreatments, likewise, a change in the size of their peaks occurred, vibrational stretching was present, and lignin signals remained apparent via, as mentioned above, characteristic groups of lignin (aromatic compounds, phenol groups, ethers present, and carbonyl groups). Notwithstanding, in the spectral range $1700-1160 \mathrm{~cm}^{-1}$, it is indicated that there is the presence of monolignans such as guayacil, as inferred by the shape of the wing and the functional groups which occur nearby [30].

With ozonolysis, some lignin is degraded causing a variety of compounds, among which are aromatic groups, phenols, alcohols, ethers, and carbonyl groups.

3.4. Determination of Enzyme Activity. Table 3 shows the results of enzymatic activity of Celluzyme XB, expressed as hydrolyzed filter paper units (FPU) per milligram of enzyme. An FPU is defined as the amount of enzyme necessary to produce a mole of reducing sugars per minute per gram of substrate [31].

3.5. Enzymatic Hydrolysis of Pretreated Cellulosic Material. The material being pretreated with the oxidizing basic treatment, for which a concentration of $0.5642 \mathrm{~g}$ reducing sugars/g biomass was obtained, favored the obtaining of reducing sugars. This was due to applying the basic oxidizing pretreatment, whereby the materials increased the size of their pores, giving greater access penetration of enzymes and therefore increased enzymatic breakdown of carbohydrates. The significant increase in the generation of reducing sugars was due to an enzymatic cocktail of cellulases and hemicellulases $(217.65 \mathrm{FPU} / \mathrm{mL})$.

The generation of total sugars was favored in all pretreatments but significantly in the basic-oxidant $(0.5642 \mathrm{~g}$ sugar/g biomass), basic $\mathrm{CaO}$ (0.4961 g sugar/g biomass), and dilute acid ( $0.3798 \mathrm{~g}$ sugars/g biomass) pretreatments. This difference could be due to a modification of the crystalline state of the cellulose, due to the implementation of basic pretreatments with $\mathrm{NaOH}$ and $\mathrm{CaO}$, having the effect of increasing the size of the pores of the cellulosic material, which stimulates more accessibility and susceptibility to attack by an amorphously structured enzyme. As the acid pretreatment degraded during the pretreatment process, many 
of the hemicellulose to cellulose bonds were held together with lignin, thus becoming more susceptible to the enzymatic attack of biomass. In general, before applying the CBM, the pretreatment increased the solubility of lignin, freeing the cellulose and thus making it available for enzymatic hydrolysis [10], highlighting the efficiency of pretreatments in obtaining acceptable levels of total sugars.

In order to understand the degradation of total and reducing sugars, the degree of polymerization (on average) of different pretreatments was calculated. Basic pretreatment with sodium hydroxide had the lowest degree of polymerization. That is, treatment promotes smaller carbohydrates, which would be more accessible to the microorganism during fermentation. Among the chemical pretreatments applied to the lignocellulosic materials is the basic pretreatment with dilute $\mathrm{NaOH}$, which increases the surface area and decreases the degree of polymerization and crystallinity by removing links between lignin and carbohydrates [12]. The value obtained depended on the cellulosic material used and the pretreatment applied to the fibrous material; hence, with the basic pretreatment using $\mathrm{NaOH}(\mathrm{GP}=5.7)$ and $\mathrm{CaO}(\mathrm{GP}=6.6)$, sugars are obtained with a lower degree of polymerization; that is, they are easier to degrade.

For carbohydrates, qualitative and quantitative analyses were performed via HPLC. The pretreatment that had the greater effect for the transformation of cellulosic material to the accessible enzyme was saccharification of dilute acid, a pretreatment that generates sugars such as xylose $(0.07069 \mathrm{~g}$ xylose/g biomass) and cellobiose $(0.02946 \mathrm{~g}$ cellobiose $/ \mathrm{g}$ biomass). Although the saccharification of pretreated cellulose with dilute $\mathrm{H}_{2} \mathrm{SO}_{4}$ showed good yields $(0.3798 \mathrm{~g}$ total sugar/g biomass), an important concentration of cellobiose was generated, indicating that the enzymatic hydrolysis was incomplete [12]. This could be explained in terms of a poor cellobiase activity inside the enzymatic cocktail.

Regarding glucose generation, the pretreatment that generates a greater concentration was the basic pretreatment with $\mathrm{NaOH}$, yielding a concentration of $0.02011 \mathrm{~g}$ glucose $/ \mathrm{g}$ biomass, and the second pretreatment that was mostly predisposed, via the CBM, to enzymatic attack oxidant was a basic pretreatment, obtaining thus a glucose concentration of $0.01668 \mathrm{~g} / \mathrm{g}$ biomass. This was due to an increased internal surface of cellulosic biomass and lower crystallinity, and due to the effect of the alkali treatment, the enzyme cocktail had greater access to the material and therefore it degraded more easily the cellulose into smaller units such as with the glucose.

Among the various pretreatments applied in this work, dilute acid pretreatment is the one that has been largely studied and significantly improves the enzymatic hydrolysis $[32,33]$. Generally, this pretreatment significantly improved the obtaining of fermentable sugars after enzymatic hydrolysis was applied to the CBM using diluted acid, made with the optimal conditions obtained via experimental design.

\section{Conclusions}

CBM is a good source of fermentable sugars. The production of ethanol from this cellulose can be an alternative product of this waste recovery. Pretreatment with acid did not generate F, while HMF concentration did not inhibit fermentation.
The evaluation of enzymatic hydrolysis of pretreated biomass showed that basic-oxidant pretreatment largely promoted enzymatic attack of the cellulose which was concluded from the observation of sugars obtained from the saccharification process that was previously pretreated. In addition, the analysis by infrared spectroscopy helped to analyze the effectiveness of each pretreatment.

\section{Conflicts of Interest}

The authors declare that they have no conflicts of interest regarding the publication of this paper.

\section{Acknowledgments}

This research was cofinanced by the Mexican Science and Technology Council (CONACyT) and Instituto Mexicano del Petróleo (IMP) through Project 151370 (Y.02000/Y.60013).

\section{References}

[1] M. W. Lau and B. E. Dale, "Cellulosic ethanol production from AFEX-treated corn stover using Saccharomyces cerevisiae 424A(LNH-ST)," Proceedings of the National Academy of Sciences of the United States of America, vol. 106, no. 5, pp. 1368 $1373,2009$.

[2] N. Lu and R. W. Rice, "Demand drivers and price supports for bioethanol use as fuel in the United States: a brief review," Forest Products Journal, vol. 60, no. 2, pp. 126-132, 2010.

[3] C. A. Cardona and Ó. J. Sánchez, "Fuel ethanol production: process design trends and integration opportunities," Bioresource Technology, vol. 98, no. 12, pp. 2415-2457, 2007.

[4] S. Imman, J. Arnthong, V. Burapatana, V. Champreda, and N. Laosiripojana, "Effects of acid and alkali promoters on compressed liquid hot water pretreatment of rice straw," Bioresource Technology, vol. 171, pp. 29-36, 2014.

[5] B. Dien and R. A. Bothast, "Primer for lignocellulose biochemical conversion to fuel ethanol," in Industrially Robust Enzymes And Microorganisms for Production of Sugars And Ethanol from Agricultural Biomass, National Center for Agricultural Utilization Research, Ed., pp. 73-93, 2009.

[6] Y. Kim, T. Kreke, R. Hendrickson, J. Parenti, and M. R. Ladisch, "Fractionation of cellulase and fermentation inhibitors from steam pretreated mixed hardwood," Bioresource Technology, vol. 135 , pp. 30-38, 2013

[7] J.-W. Lee and T. W. Jeffries, "Efficiencies of acid catalysts in the hydrolysis of lignocellulosic biomass over a range of combined severity factors," Bioresource Technology, vol. 102, no. 10, pp. 5884-5890, 2011.

[8] E. Palmqvist and B. Hahn-Hägerdal, "Fermentation of lignocellulosic hydrolysates. I: inhibition and detoxification," Bioresource Technology, vol. 74, no. 1, pp. 17-24, 2000.

[9] P. M. Kumar, D. M. Barrett, M. J. Delwiche, and P. Stroeve, "Methods for pretreatment of lignocellulosic biomass for efficient hydrolysis and biofuel production," Industrial and Engineering Chemistry Research, vol. 48, no. 8, pp. 3713-3729, 2009.

[10] P. Alvira, E. Tomás-Pejó, M. Ballesteros, and M. J. Negro, "Pretreatment technologies for an efficient bioethanol production process based on enzymatic hydrolysis: a review," Bioresource Technology, vol. 101, no. 13, pp. 4851-4861, 2010. 
[11] A. Sluiter, B. Hames, R. Ruiz, C. Scarlata, J. Sluiter, and D. Templeton, "Determination of ash in biomass," Tech. Rep. NREL/TP-510-42622, National Renewable Energy Laboratory, 2008.

[12] A. Sluiter, B. Hames, R. Ruiz, C. Scarlata, J. Sluiter, and D. Crocker, "Determination of structural carbohydrates and lignin in biomass," Tech. Rep. NREL/TP-510-42618, 2011.

[13] M. Dubois, K. A. Gilles, J. K. Hamilton, P. A. Rebers, and F. Smith, "Colorimetric method for determination of sugars and related substances," Analytical Chemistry, vol. 28, no. 3, pp. 350356, 1956.

[14] G. L. Miller, "Use of dinitrosalicylic acid reagent for determination of reducing sugar," Analytical Chemistry, vol. 31, no. 3, pp. 426-428, 1959.

[15] L. A. Ramos, J. M. Assaf, O. A. El Seoud, and E. Frollini, "Influence of the supramolecular structure and physicochemical properties of cellulose on its dissolution in a lithium chloride/N,N-dimethylacetamide solvent system," Biomacromolecules, vol. 6, no. 5, pp. 2638-2647, 2005.

[16] D. Aragon, M. Suhr, and V. Kochergin, "Evaluation of energy cane and sweet sorghum as feedstocks for conversion into fuels and chemicals," Sugar Industry-Zuckerindustriee, vol. 138, no. 10, pp. 651-655, 2013.

[17] D. C. Montgomery, Design and Analysis of Experiments, Wiley, Hoboken, NJ, USA, 1991.

[18] M. Li, Z. Yang, M. Yang, L. Shan, and J. Dong, "Determination of furfural in beer by high-performance liquid chromatography with solid-phase extraction," Journal of the Institute of Brewing, vol. 115, no. 3, pp. 226-231, 2009.

[19] Z. Xue, L. Wang, and L. De-Hua, "Peracetic acid pretreatment of sugarcane bagasse for enzymatic hydrolysis: a continued work," Journal of Chemical Technology and Biotechnology, vol. 83, no. 6, pp. 950-956, 2008.

[20] M. Das, P. Saprativ, R. Ravindran, and D. Deka, "Bioethanol production from leafy biomass of mango (Mangifera indica) involving naturally isolated and recombinant enzymes," Preparative Biochemistry and Biotechnology, vol. 43, no. (7), pp. 717734, 2013

[21] A. T. W. M. Hendriks and G. Zeeman, "Pretreatments to enhance the digestibility of lignocellulosic biomass," Bioresource Technology, vol. 100, no. 1, pp. 10-18, 2009.

[22] S. Tian, J. Zhu, and X. Yang, "Evaluation of an adapted inhibitortolerant yeast strain for ethanol production from combined hydrolysate of softwood," Applied Energy, vol. 88, no. 5, pp. 1792-1796, 2011.

[23] S. Bower, R. Wickramasinghe, N. J. Nagle, and D. J. Schell, "Modeling sucrose hydrolysis in dilute sulfuric acid solutions at pretreatment conditions for lignocellulosic biomass," Bioresource Technology, vol. 99, no. 15, pp. 7354-7362, 2008.

[24] C. Xiros, C. Vafiadi, T. Paschos, and P. Christakopoulos, "Toxicity tolerance of Fusarium oxysporum towards inhibitory compounds formed during pretreatment of lignocellulosic materials," Journal of Chemical Technology and Biotechnology, vol. 86, no. 2, pp. 223-230, 2011.

[25] M. E. Lienqueo, M. C. Ravanal, R. Pezoa-Conte et al., "Second generation bioethanol from Eucalyptus globulus Labill and Nothofagus pumilio: ionic liquid pretreatment boosts the yields," Industrial Crops and Products, vol. 80, pp. 148-155, 2016.

[26] R. Maryana, D. Ma'rifatun, I. A. Wheni, K. W. Satriyo et al., "Alkaline pretreatment on sugarcane bagasse for bioethanol production," Energy Procedia, vol. 47, pp. 250-254, 2014.
[27] R. Pezoa, V. Cortinez, and S. Hyvarinen, "Use of ionic liquids in the pretreatment of forest and agricultural residues for the production of bioethanol," Cellulose Chemistry and Technology, vol. 44, no. 4-6, pp. 165-172, 2010.

[28] I. A. Pearl, The Chemistry of Lignin, Marcel Dekker Inc, New York, NY, USA, 1967.

[29] R. Singh, S. Singh, K. D. Trimukhe et al., "Lignin-carbohydrate complexes from sugarcane bagasse: preparation, purification, and characterization," Carbohydrate Polymers, vol. 62, no. 1, pp. 57-66, 2005

[30] M. Sarwar, D. Nasima, M. Islam, and S. M. Moeiz, "Characterization of lignin isolated from some nonwood available in Bangladesh," Bioresource Technology, vol. 98, no. 2, pp. 465-469, 2007.

[31] T. S. Nordmark, A. Bakalinsky, and M. H. Penner, "Measuring cellulase activity: application of the filter paper assay to low-activity enzyme preparations," Applied Biochemistry and Biotechnology, vol. 137-140, no. 1-12, pp. 131-139, 2007.

[32] E. Tomás-Pejó, J. M. Oliva, A. González, I. Ballesteros, and M. Ballesteros, "Bioethanol production from wheat straw by the thermotolerant yeast Kluyveromyces marxianus CECT 10875 in a simultaneous saccharification and fermentation fed-batch process," Fuel, vol. 88, no. 11, pp. 2142-2147, 2009.

[33] Y. Kim, R. Hendrickson, N. S. Mosier et al., "Enzyme hydrolysis and ethanol fermentation of liquid hot water and AFEX pretreated distillers' grains at high-solids loadings," Bioresource Technology, vol. 99, no. 12, pp. 5206-5215, 2008. 

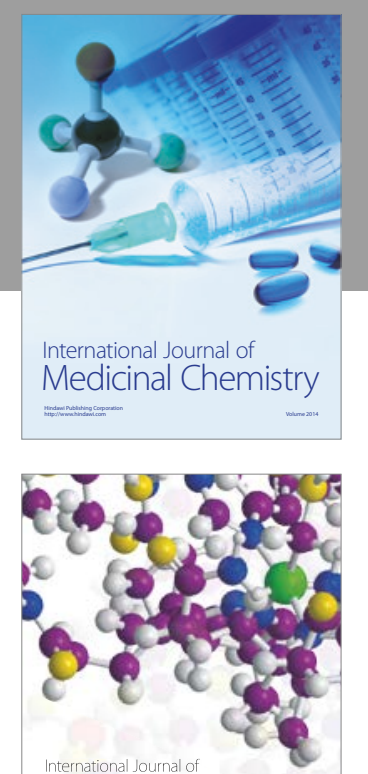

Carbohydrate Chemistry

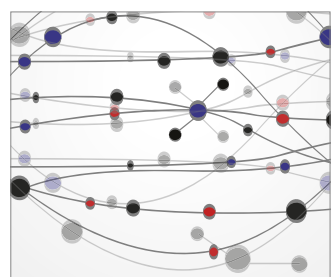

The Scientific World Journal
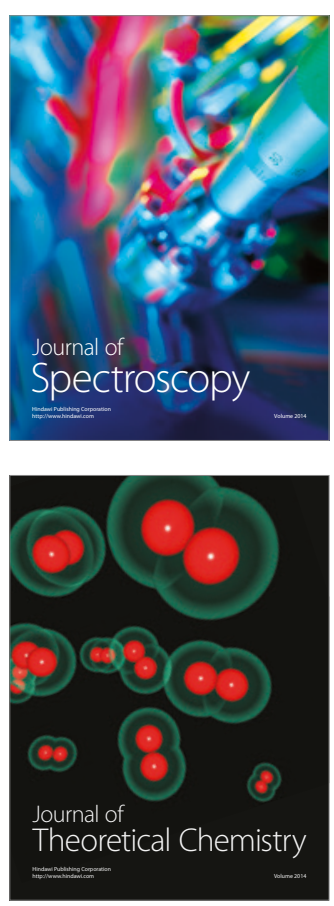
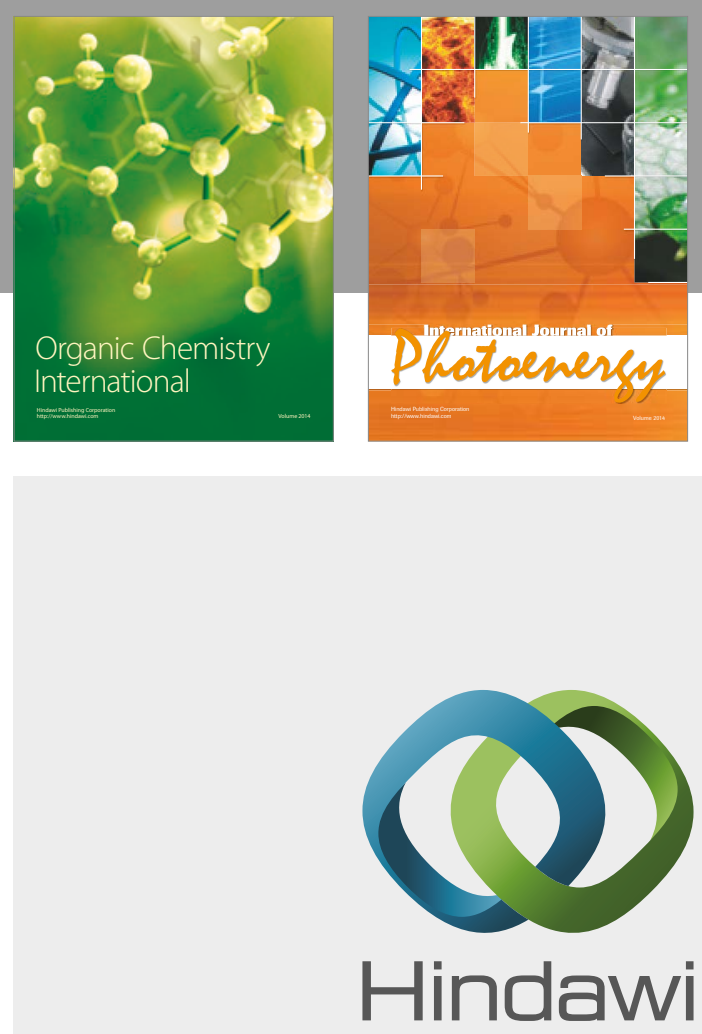

Submit your manuscripts at

https://www.hindawi.com

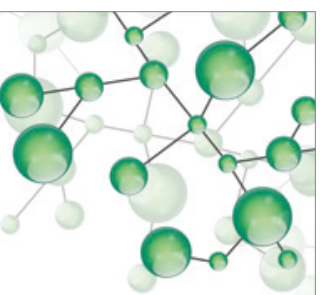

International Journal of

Inorganic Chemistry

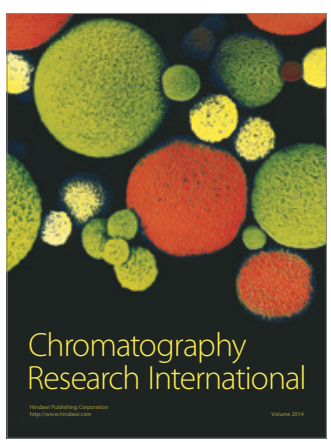

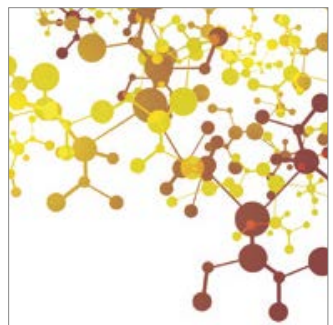

Applied Chemistry
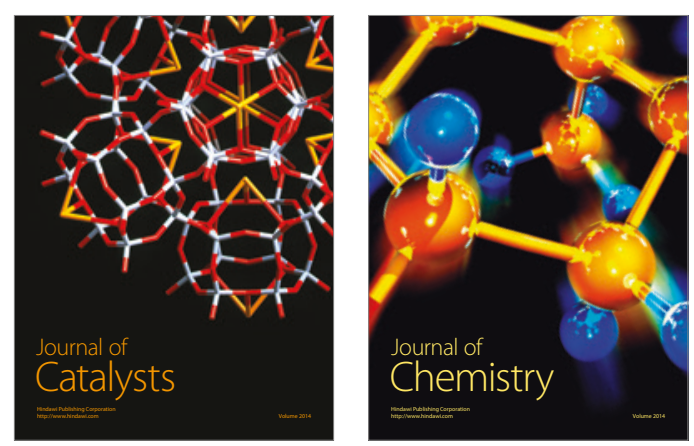
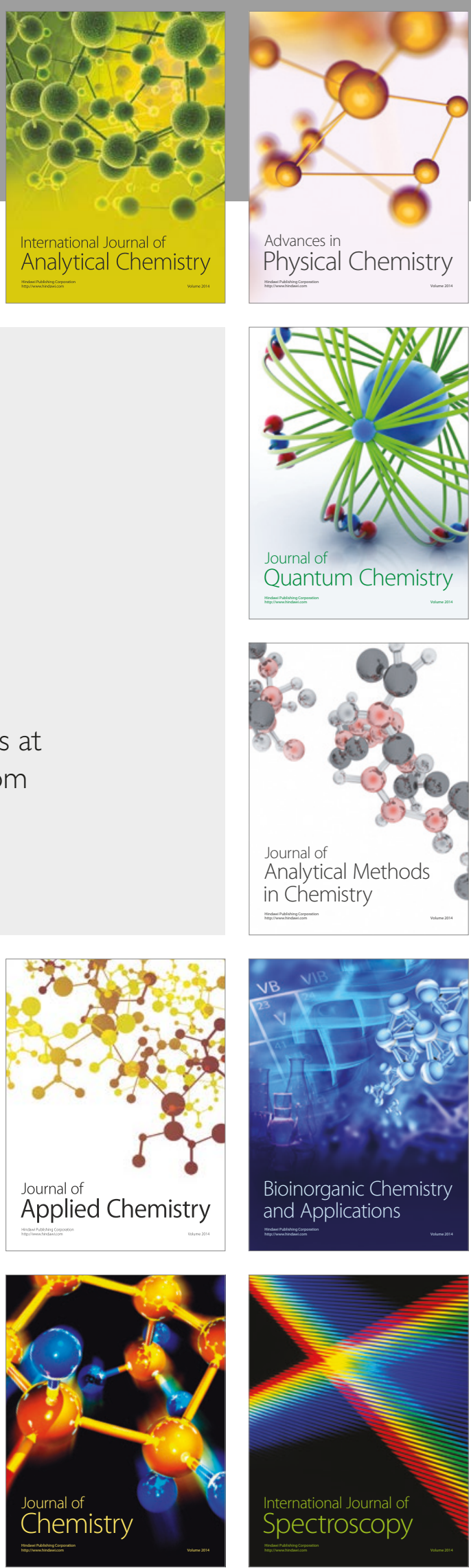